\title{
"Project-based learning" na engenharia: uma experiência prática de aprendizado lúdico em ambiente real
}

\author{
Project-based Learning in engineering: a practical experience of ludic learning in real \\ environment
}

Fernando Pires da Silva ${ }^{1}$, Letícia Moreno Oestreich ${ }^{2}$, Ana Luiza Tupam Miguel Moreno ${ }^{3}$, Guilherme Auler ${ }^{4}$, Bruno Pereira do Nascimento ${ }^{5}$, Tailor Johan ${ }^{6}$, Celso Becker Tischer ${ }^{7}$, Valéria Rolim Marostega, Bruna Fuzzer de Andrade ${ }^{9}$ e Alejandro Ruiz-Padillo ${ }^{10}$

\begin{abstract}
1,3,4,5,6,7,8,9 Universidade Federal de Santa Maria, Campus Cacheira do Sul, Cachoeira do Sul, Brasil 00149742@ufrgs.br,anatmmoreno@hotmail.com,guigoauler@gmail.com, bruinonasc@outlook.com, tailorjohann@yahoo.com.br, cbtischer@gmail.com, arq.valeria@hotmail.com, bruna.fuzzer@windowslive.com
\end{abstract}

${ }^{2}$ Laboratório de Mobilidade e Logística, Universidade Federal de Santa Maria, Campus de Cachoeira do Sul, Brasil leticia.oestreich@hotmail.com

${ }^{10}$ Laboratório de Mobilidade e Logística, Universidade Federal de Santa Maria, Campus de Cachoeira do Sul, Brasil alejandro.ruiz-padillo@ufsm.br

\section{Resumo}

As exigências e desafios apresentados atualmente pelo mercado de trabalho nas áreas de engenharia e arquitetura exigem dos futuros profissionais uma formação mais prática e crítica que facilite a resolução de problemas. Sendo assim, fica evidente que as metodologias tradicionais utilizadas nesses cursos precisam ser modificadas para possibilitar uma adequada capacitação além de apenas conhecimentos teóricos da área, como comunicação oral, trabalho em equipe e liderança de grupos, entre outros. O ensino baseado em Project Based Learning (PBL) proporciona aos alunos experiências interdisciplinares que fortalecem essas aptidões, envolvendo os estudantes com projetos de tomada de decisão semelhantes àqueles vivenciados na vida profissional. O objetivo deste trabalho é mostrar as experiências vivenciadas pelos alunos dos cursos da Universidade Federal de Santa Maria - Campus Cachoeira do Sul na aplicação dessa metodologia inovadora de ensino. Como principais resultados, os estudantes desenvolveram tarefas relacionados a estudos de casos reais na área científico-técnica, com a apresentação de trabalhos a especialistas, entrega de relatórios e desenvolvimento de protótipos. A aplicação da metodologia se tornou satisfatória e motivadora, uma vez que estimulou o trabalho em equipe, integração das áreas da engenharia e arquitetura, troca de experiências entre alunos e professores e integração com a comunidade.

Palavras-chave: Interdisciplinaridade; Projetos; Metodologia de ensino

\section{Abstract}

The demands and challenges currently presented by the labour market in the engineering and architecture areas require future professionals to have a more practical and critical training in order to facilitate problem solving. Thus, it is evident that the traditional methodologies used in these courses need to be modified to enable adequate training beyond theoretical knowledge in the area, such as oral communication, teamwork and group leadership, among others. Project Based Learning $(P B L)$ teaching provides interdisciplinary experiences for students with the aim of strengthening these attitudes, involving students with decision-making projects similar to those experienced in professional life. The objective of this work is to show the experiences of the students of the Federal University of Santa Maria - Campus Cachoeira do Sul in the application of this innovative teaching methodology. As main results, the students developed academic tasks related to real case studies in the scientific-technical area, with the presentation of their work to specialists, report delivery and prototype development. The application of the methodology became satisfactory and motivating, since it stimulated teamwork, integration of engineering and architecture areas, exchange of experiences between students and teachers and integration with the community.

Keywords: Interdisciplinarity; Projects; Teaching methodology 


\section{Introdução}

As engenharias tem um papel muito importante no desenvolvimento de inovações tecnológicas e fomentação da competitividade nas indústrias. Entretanto, tem-se verificado que, com a atual metodologia de ensino, a formação dos profissionais se dedica ao aprendizado técnico e teórico das disciplinas, mas tem esquecido de fortalecer as questões básicas que envolvem habilidades comunicativas, expressão oral e conhecimento de outras línguas (CONFEDERAÇÃO NACIONAL DA INDUSTRIA, 2015).

Por outro lado, as taxas de desistência dos cursos de engenharia no Brasil têm crescido alarmantemente nos últimos anos. Segundo a pesquisa do Censo de Educação Superior-INEP, para o ano de 2010 a taxa era de 12,4\% tendo um salto em 2015 para 56,4\% (INEP, 2015). Percebe-se, que mais da metade dos alunos que ingressam nos cursos de engenharia acabam desistindo de se formarem. Esses resultados estatísticos refletem na qualidade da profissão, acarretando em uma carência de profissionais capacitados para atuarem na área.

Para Nguyen (1998) algumas das habilidades que formam o atributo atitude de um profissional da área da engenharia incluem a competência, integridade, comprometimento, tolerância, flexibilidade e compromisso com a aprendizagem. Dentre essas habilidades àquelas requeridas pela indústria, a principal é a atitude do profissional, seguida as competências técnicas e intelectuais.

Portanto, a engenharia contemporânea necessita de profissionais competentes que possuam além do conhecimento técnico da engenharia. Ou seja, profissionais com habilidades relacionadas à adaptação as mudanças tecnológicas e organizacionais no ambiente de trabalho, sabendo lidar com diversas situações que exijam a tomada de decisão, além de dominarem assuntos jurídicos, comerciais, econômicos e de gestão (MILLS e TREAGUST, 2003).

Entretanto, no método de ensino tradicional dos cursos de engenharia esses estímulos não são reforçados, pois o aluno é somente um agente passivo da informação, ficando o professor como agente ativo que repassa os conhecimentos referente às teorias e práticas do conteúdo abordado. O aluno, por sua vez, apenas recebe os aprendizados sem o dever de expressar sua opinião ou elaborar trabalhos que exijam a tomada de decisão (SILVA, 2000).

Portanto, no aprendizado tradicional os alunos de engenharia possuem uma deficiência na sua formulação das competências técnicas das quais serão de sua atribuição depois de formados. Além disso, não desenvolvem uma comunicação humana, carência que dificultará a sua habilidade de expressão em público e consequentemente prejudicará seu futuro profissional (RIBEIRO, 2005).

A Pirâmide da Aprendizagem proposta por Dale (1946) diz que o aprendizado é bem sucedido, em 70\%, quando se discute sobre o assunto abordado, em $80 \%$, quando se desenvolve e em $95 \%$, quando se ensina, ou seja, se transmite a outros indivíduos, enquanto que mediante metodologias voltadas a somente a ler, ouvir ou observar o aprendizado é alcançado em no máximo 30\%. Nesse contexto, o desenvolvimento de técnicas de aprendizagem que estimulem a comunicação entre os alunos e desenvolvam habilidades do processo de tomada de decisão se tornam importantes no processo de formação dos novos engenheiros. A técnica denominada Project-Based Learning (PBL) é um modelo de aprendizagem no qual os alunos são expostos a projetos que demandam tempo para serem executados, em que as tarefas são caracterizadas como complexas ou desafiadoras dando a oportunidade dos estudantes trabalharem na tomada de decisão de situações que se assemelham às vivenciadas pela vida profissional (THOMAS, 2000).

O emprego de técnicas de aprendizado PBL proporciona aos alunos a oportunidade de se capacitarem de uma forma atrativa e inovadora, sendo uma técnica multidisciplinar que auxilia no desenvolvimento do aprendizado em diversas disciplinas (BARROWS, 1984). Nas experiências reportadas em um estudo realizado por Ribeiro (2005) o uso de práticas de aprendizagem relacionadas ao PBL é oportuno tanto para os alunos dos cursos de engenharia - pelo desenvolvimento de habilidades que lhes serão uteis na sua vida academia e profissional - quanto para os docentes que ministram disciplinas nesses cursos. O autor esclarece que o professor tem a oportunidade de reconhecer o funcionamento do raciocínio dos seus alunos e seus respectivos interesses e dificuldades, assim podendo melhorar suas táticas pedagógicas, adequando-se à realidade dos discentes.

O estudo de Trasobares e Gilaberte (2007) mostra a experiência multidisciplinar com o PBL aplicado a alunos da Escola Politécnica de Teruel da Universidade de Zaragoza (Espanha). Os principais aspectos positivos da aplicação do método do projeto incluem o desenvolvimento de habilidades de autoaprendizagem, comunicação e trabalho em equipe. O autor aponta que as dificuldades vivenciadas pelos estudantes na elaboração do projeto foram a falta de tempo, dificuldades com o comprimento do plano e sensação da falta de ajuda dos professores. Entretanto, esses obstáculos sentidos pelos alunos representam a sua falta de habilidade com a aplicação de metodologias PBL, dado pelo hábito aos métodos mais tradicionais.

Esses resultados demonstram que a aplicação dessas metodologias trazem benefícios para todos os envolvidos. Pode-se afirmar que a aplicação dessas práticas se tornam importantes para a comunidade em que a instituição de ensino está inserida também, visto que algumas disciplinas dos cursos permitem a aplicação de projetos metodológicos voltados à interação com a comunidade. Esse é o caso de estudo apresentado pelos autores Passos, Herdy e Passos (2010), em que os alunos desenvolveram projetos em sala de aula que passaram por avaliação de comunidade externa, sendo que as melhores soluções do problema foram repassadas à comunidade posteriormente. 
Com base nisso, o objetivo deste trabalho é mostrar os resultados obtidos da aplicação de metodologia de ensino baseada no Project-Based Learning nos cursos de Engenharias e Arquitetura e Urbanismo da Universidade Federal de Santa Maria no Campus Cachoeira do Sul (UFSM-CS). Em especial, serão expostas as práticas aplicadas em disciplinas do curso de Engenharia de Transportes e Logística e as experiências interdisciplinares realizadas junto a alunos e docentes dos cursos de Engenharia Elétrica e de Arquitetura e Urbanismo. Busca-se, com a aplicação dessas iniciativas, a capacitação técnica dos alunos nas disciplinas específicas mediante técnicas e métodos práticos considerados de vanguarda na Educação e aproximação direta à realidade das áreas vinculadas.

\section{Metodologia}

A metodologia utilizada no desenvolvimento deste trabalho é baseada no Project-Based Learning. A técnica é dita como um recurso didático centrado no aluno, fazendo deste o principal agente responsável pelo seu aprendizado, em pequenos grupos e sob a orientação de um tutor (professor/orientador). Nesta metodologia, os problemas são apresentados ao aluno na sequência de aprendizagem como uma ferramenta para alcançar o conhecimento necessário para sua resolução e desenvolver habilidades de trabalho colaborativo (MICHAELSEN et al., 2004; YIN, 2001).

Além disso, a metodologia incorpora às atividades práticas um aspecto lúdico que contribui no aumento de interesse e dedicação dos alunos (BARROWS, 1984). A utilização de jogos educacionais como instrumentos auxiliares no processo de aprendizagem trazem igualmente um comprometimento dos alunos nas atividades. Nesse contexto, essas metodologias ajudam no desenvolvimento da criatividade e motiva os alunos no desenvolvimento da tarefa (CARDOSO et al., 2015).

Por outro lado, as atividades vinculadas ao desenvolvimento do trabalho em equipe são previstas em técnicas denominadas Team-Based Learning, na qual objetivam o envolvimento dos alunos em trabalhos colaborativos. Os alunos desenvolvem e gerenciam equipes de trabalho, avaliam o trabalho dos colegas e se comprometem individualmente para o bem da equipe para adquirir confiança entre colegas (MICHAELSEN et al., 2004; CHANG et al., 2015). Esses trabalhos podem ser desenvolvidos tanto em sala de aula quanto extra-classe e, finalmente, os resultados dos trabalhos costumam ser expostos ou apresentados pela equipe à turma, também como modo de avaliação por parte do professor.

Portanto, o presente trabalho baseia-se em uma metodologia que une as técnicas relacionadas a jogos educacionais, Project-based Learning e Team-Based Learning (Figura 1), transformando o método em uma proposta lúdica, real e didática de aprendizado nas disciplinas voltadas às áreas específicas da engenharia fazendo com que o aluno tenha uma proximidade com a área de atuação profissional e saiba desenvolver processos de tomada de decisão coerentes com os aprendizados técnicos. Da mesma maneira, a metodologia busca promover também a interação entre os colegas e oportunidades de trocas de ideias entre alunos, professores e profissionais atuantes na área.

Figura 1 - Apresentação da metodologia utilizada

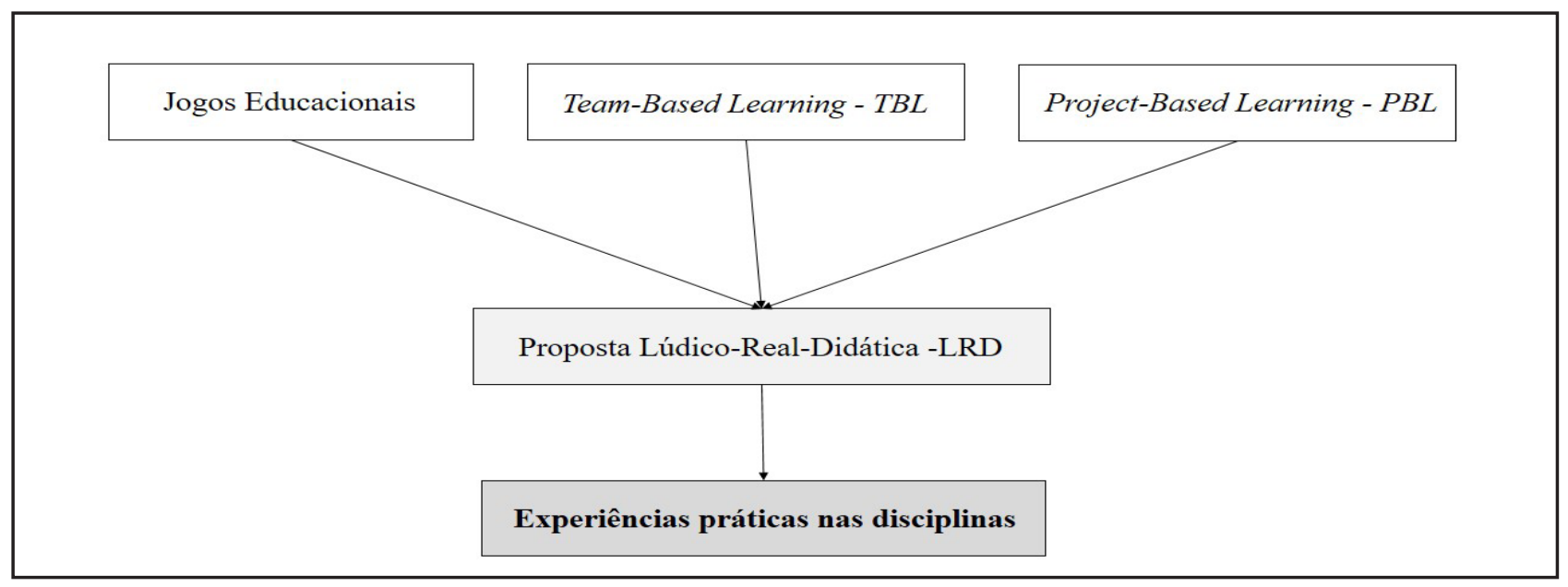

\section{Resultados}

A seguir são apresentados os resultados de duas experiências diferentes desenvolvidas a partir da aplicação da metodologia de ensino proposta em disciplinas dos cursos de Engenharia de Transportes e Logística e de Engenharia Elétrica da UFSM-CS, durante o segundo semestre de 2017 e primeiro semestre de 2018 . 


\subsection{Experiência na disciplina de Projeto Geométrico de Rodovias}

A aplicação da metodologia descrita na disciplina Projeto Geométrico de Rodovias do curso de Engenharia de Transportes e Logística iniciou-se com a proposta de os alunos da referida disciplina da UFSM participarem do "Projeto Ponto de Partida" (Garcia et al, 2017), projeto este que já vem sendo aplicado com os alunos da disciplina de Rodovias do curso de Engenharia Civil da Universidade Federal do Rio Grande do Sul - UFRGS desde o primeiro semestre de 2016. O projeto aplica a metodologia do PBL, aliada à simulação de um ambiente lúdico-real-didático, para a elaboração do projeto geométrico e de terraplenagem de um trecho de rodovia em que os alunos formam equipes de trabalho que concorrem como empresas em um processo de licitação para conseguir o melhor projeto. A ideia geral era seguir as etapas do projeto em sincronia com os alunos da UFRGS para que, no final do semestre, o trabalho da UFSM fosse apresentado como um dos projetos competindo no mesmo processo licitatório.

O projeto proposto pela disciplina foi elaborado em duas etapas: (I) Estudo de Viabilidade Técnica, Econômica e Ambiental - EVTEA, entregue e apresentado em uma Audiência Pública; (II) Projeto Executivo de Engenharia para construção da rodovia, entregue na Abertura dos Envelopes, contendo os documentos referentes ao Projeto Geométrico e o Projeto de Terraplenagem, que foram avaliados através de indicadores de desempenho. Dessa forma, os alunos presentes na disciplina assinaram um contrato social para a formação de uma empresa fictícia para elaboração do projeto como participantes do projeto Ponto de Partida. A elaboração do trabalho exigiu dos alunos o domínio sobre softwares de geoprocessamento, como QGIS e SAEPRO, para isso foram disponibilizados tutoriais no ambiente virtual da disciplina (moodle). O projeto teve como base os documentos referentes ao edital e o termo de referência com as especificações do serviço requerido.

Figura 2 - Diretriz provisória do traçado de trecho rodoviário com buffer de 250m apresentado em Audiência Pública simulada na disciplina de Projeto Geométrico de Rodovias

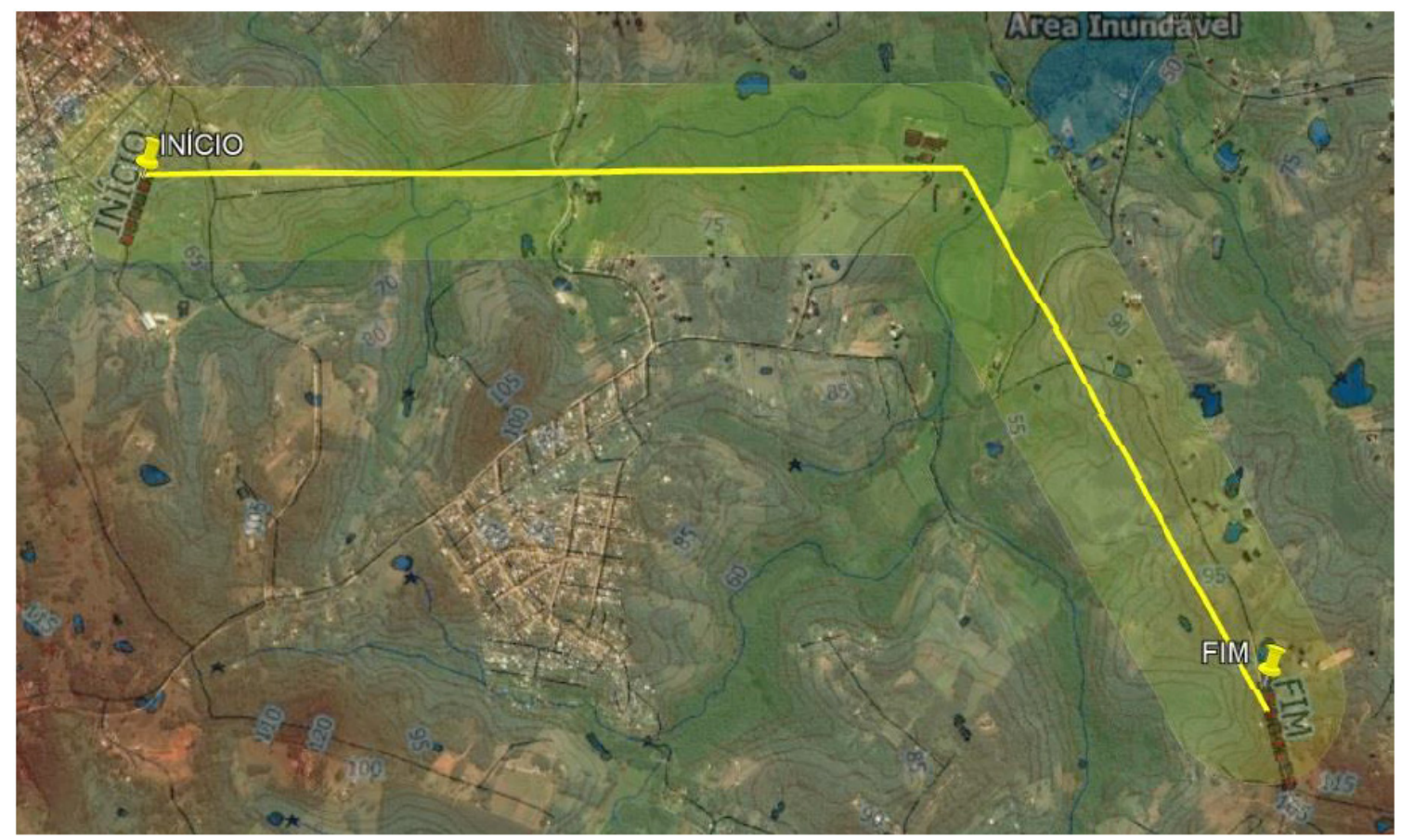

Como forma de auxiliar os alunos no processo de desenvolvimento do projeto, foi proposta à equipe ao longo da disciplina a elaboração atividades práticas de forma a constituir o acervo técnico da empresa simulando ARTs (Anotações de Responsabilidade Técnica). Portanto, ao final de cada aula, os estudantes realizavam as atividades práticas avaliativas referentes aos conteúdos do projeto (planimetria, altimetria, seções transversais, cálculo de volume de terraplenagem e distribuição de volumes). Seguindo um cronograma pré-definido, essas avaliações permitiram que a equipes obtivesse a qualificação necessária para concorrer no processo e participar da etapa final de abertura de envelopes, mediante um sistema de pontuação em equipe e individual.

Para a entrega da primeira etapa, onde consta o EVTEA para a implantação do trecho rodoviário, foi proposta aos alunos a definição de uma Diretriz provisória do traçado que servisse como base para a realização de um levantamento fotogramétrico que fornecesse os dados cartográficos necessários para a definição da diretriz final. Para escolha do trajeto base, os estudantes avaliaram a viabilidade dessa diretriz com base em características relacionadas às condicionantes do relevo, cursos d'agua, rede viária, áreas verdes e áreas urbanas. A diretriz provisória foi formada por um buffer de 250 metros para cada lado, dentro da qual, na seguinte etapa, os alunos deveram escolher o melhor traçado da rodovia conforme as recomendações da norma. O 
processo de avaliação introduzia critérios de penalização mediante os indicadores calculados, caso qualquer trecho saísse dessa área, devido ao preço de levantamento de um novo voo aéreo para análise das condicionantes locais. Na Figura 2 é exposta a diretriz provisória do traçado apresentada pelos alunos na disciplina.

Para a análise dessa etapa, a Audiência Pública simulada contou com a participação de uma banca composta por profissionais na área para avaliação do estudo apresentado desde os pontos de vista da inserção no terreno, cumprimento da norma de projeto geométrico e impactos gerados ao entorno, assim como a adequação do uso das técnicas de geoprocessamento, de reconhecimento das características geológicas do terreno e de atendimento à demanda de mobilidade exigida.

Na Figura 3 é apresentado o modelo do traçado final do projeto, produto de todo o estudo realizado pelos alunos da disciplina na UFSM. Nessa atividade, os alunos e professores tiveram a oportunidade de trocar experiências, além de que o contato entre as duas universidades constituiu uma experiência ainda mais enriquecedora e motivadora para os envolvidos nas disciplinas mediante a aplicação conjunta da metodologia de ensino inovadora (Figura 4).

Figura 3 - Traçado final da rodovia apresentado na Abertura dos Envelopes na concorrência simulada na disciplina de Projeto Geométrico de Rodovias

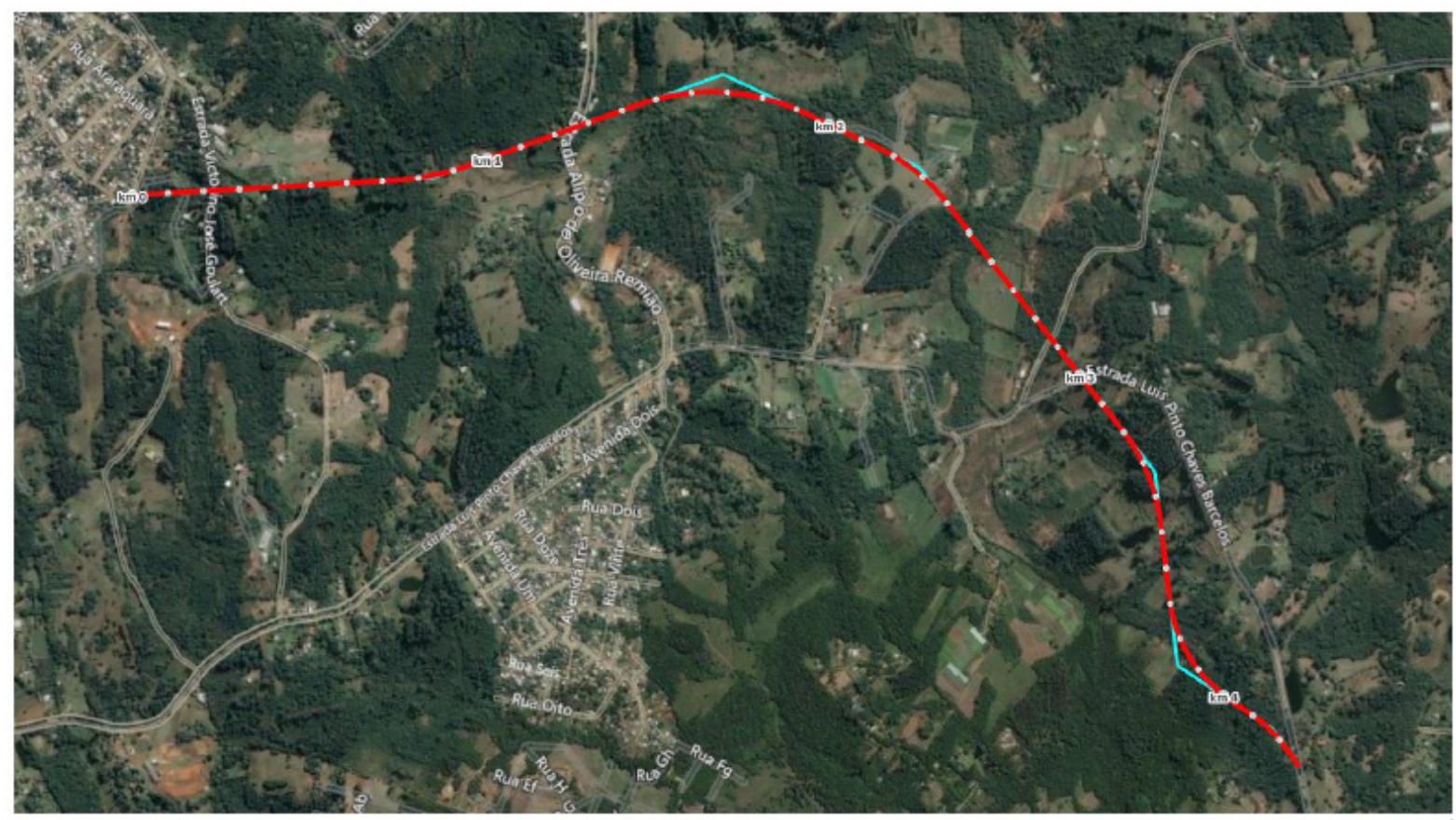

Figura 4 - Participantes da UFRGS e UFSM na Abertura dos Envelopes na concorrência simulada na disciplina de Projeto Geométrico de Rodovias

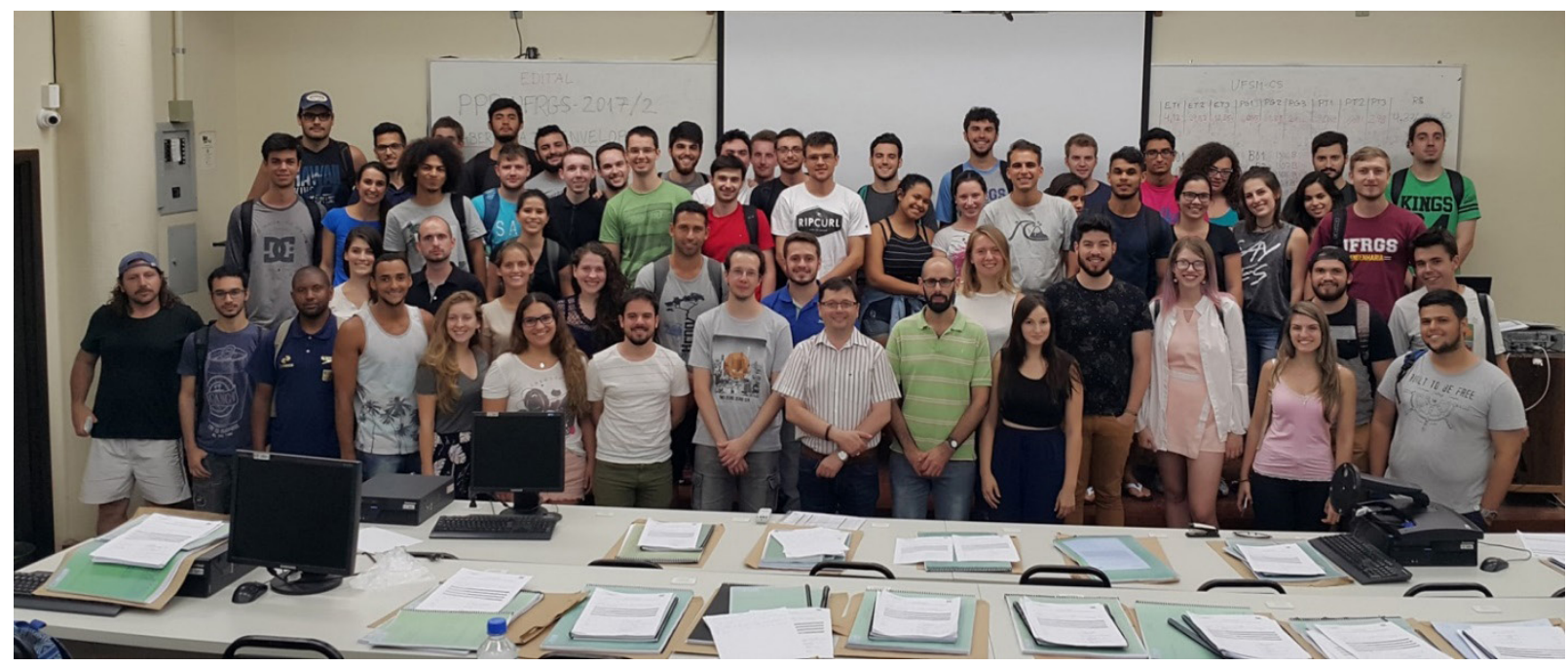




\subsection{Experiência interdisciplinar entre Engenharia de Tráfego e Análise e Projeto de Sistemas Lógicos Programáveis}

A segunda experiência apresentada nesta seção procede da aplicação interdisciplinar da metodologia de ensino em duas disciplinas de áreas diferentes, sendo uma a de Engenharia de Tráfego II, do Curso de Engenharia de Transportes e Logística, e a outra a de Análise e Projeto de Sistemas Lógicos Programáveis, do Curso de Engenharia Elétrica. Em um primeiro momento, os alunos de Engenharia de Tráfego II realizaram uma atividade de análise da sinalização semafórica de uma interseção real de três aproximações na área urbana de Cachoeira do Sul. Esta análise teve como base os métodos e conceitos de instalação, controle e programação semafórica estudados na referida disciplina.

O experimento foi divido em quatro etapas: (i) dados geométricos e de movimentos da interseção; (ii) realização da contagem classificatória de fluxos de tráfego (veículos e pedestres), com movimentos de virada; (iii) contagem de tempos de programação semafórica vigentes na interseção (verde, amarelo, vermelho e vermelho geral, e conferência das fases e estágios dos semáforos); e (iv) contagem de tempos de passagens dos veículos para o cálculo do fluxo de saturação de cada aproximação. $\mathrm{Na}$ Figura 5 são apresentadas, no formato de um croqui, as características levantadas na coleta de dados da interseção estudada, e na Figura 6 são representados os diagramas de estágios dos grupos semafóricos existentes.

Figura 5 - Representação da interseção semaforizada com os dados geométricos e de movimentos permitidos estudada na disciplina de Engenharia de Tráfego II

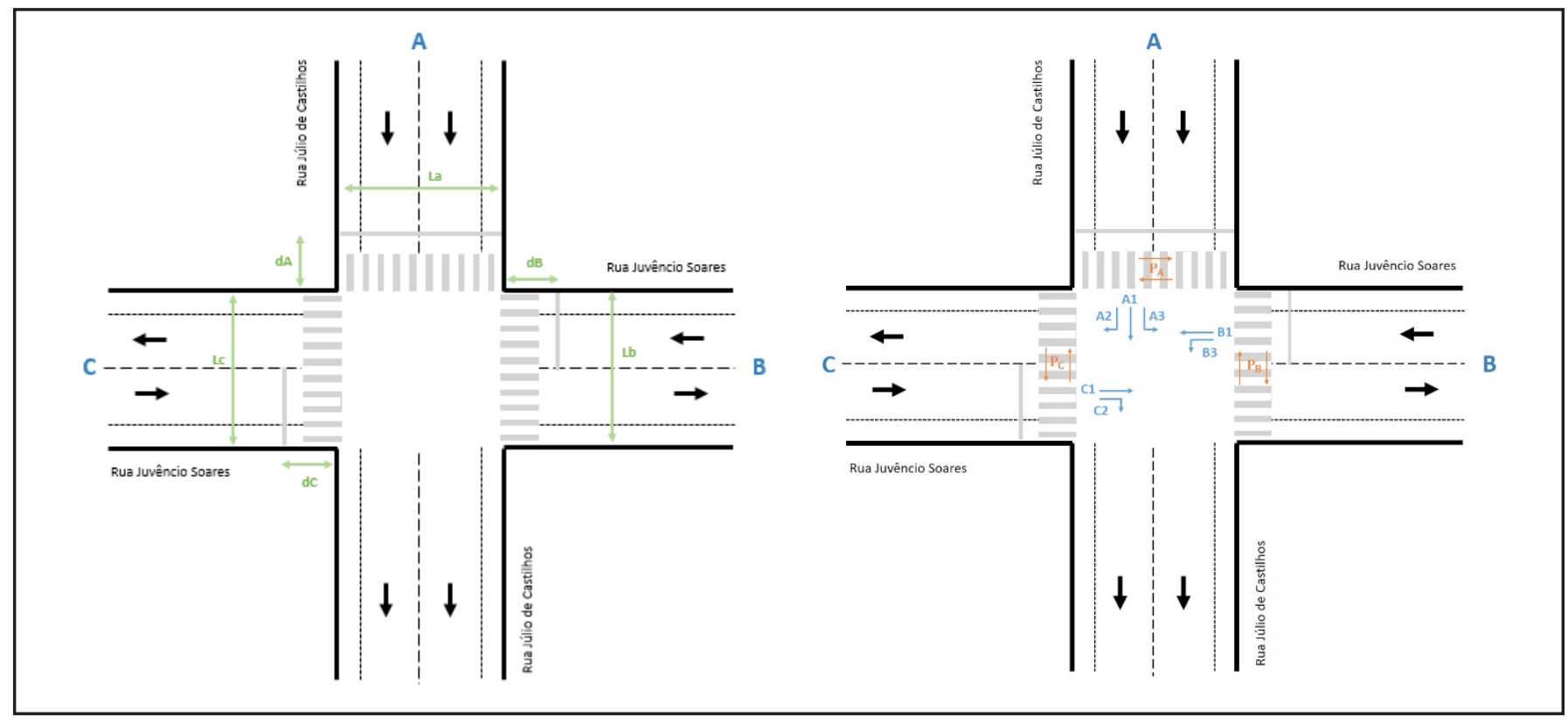

Figura 6 - Diagrama de estágios da interseção semaforizada estudada na disciplina de Engenharia de Tráfego II

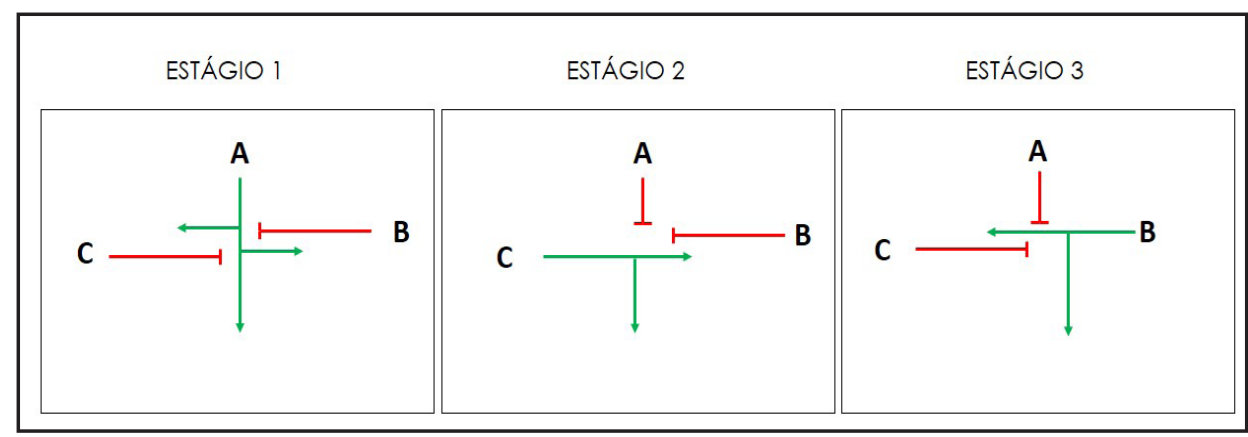

Após o levantamento dos dados, o que permitiu uma melhor compreensão na prática dos conceitos estudados na teoria em sala de aula, e de posse de todos os dados necessários para o cálculo e a definição de um semáforo com os tempos ideais para a interseção, foi proposto aos alunos que entregassem um relatório completo sobre a sinalização semafórica do local. Esse relatório conteve todos os dados vigentes da sinalização semafórica da interseção, com a análise técnica da situação, o cálculo e o resultado de como seria o arranjo e a programação semafórica ideais para a interseção em estudo. O diagrama de barras da programação semafórica obtida para a interseção em estudo é apresentado na Figura 7. 
Figura 7 - Diagrama de barras da programação semafórica proposta para a interseção estudada na disciplina de Engenharia de Tráfego II

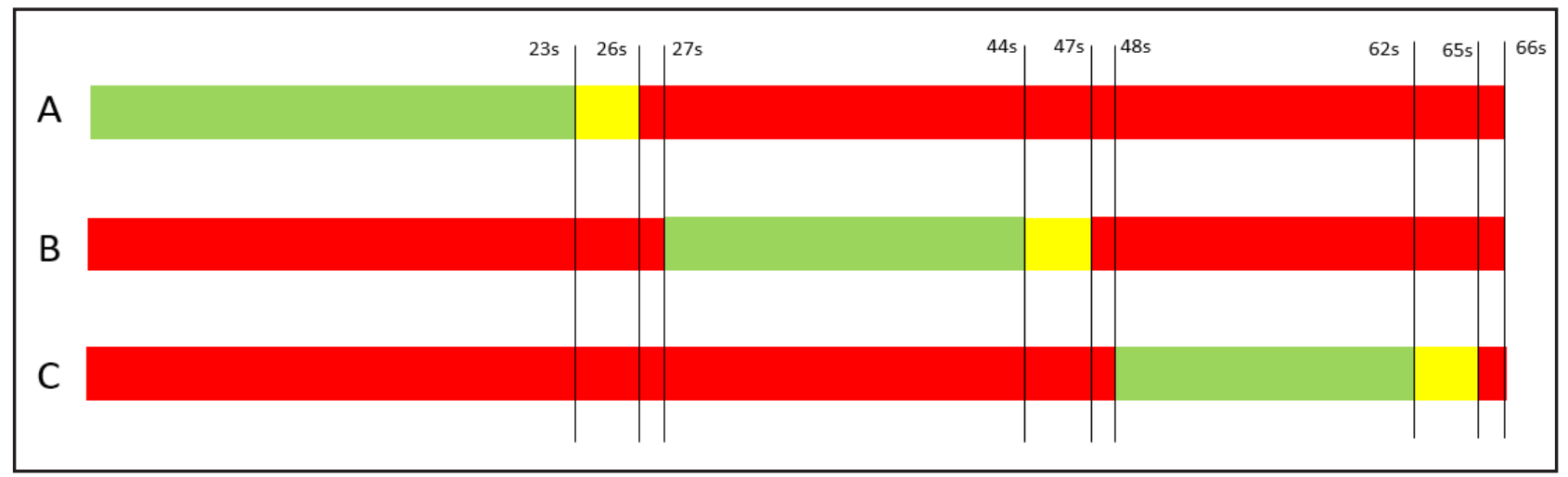

Em um segundo momento, os alunos da disciplina de Análise e Projeto de Sistemas Lógicos Programáveis realizaram uma atividade prática em sala de aula para o desenvolvimento de projetos real a partir dos tempos ideais da interseção semaforizada obtidos na disciplina de Engenharia de Tráfego II. Assim, foi proposto o controle semafórico da interseção de três aproximações, tal como mostrado na Figura 5, através da Linguagem de Descrição de Hardware (VHDL) aplicado em FPGA (Field Programmable Gate Array). Esta tecnologia é amplamente utilizada por proporcionar uma solução imediata em diversos ramos da Engenharia Elétrica descartando a necessidade da confecção de placas de circuito impresso.

O projeto proposto pela disciplina foi repassado aos alunos contendo requisitos obrigatórios, no qual o usuário final da programação desenvolvida tivesse a capacidade de trabalhar com três modos de operação, sendo eles: Modo 1 - Acionar os semáforos com tempos pré-determinados salvos na memória da placa FPGA da Altera, família Cyclone IV - Módulo 4CE115; Modo 2 - Entrar com os tempos de todos os estágios vigentes na interseção (verde, amarelo, vermelho e vermelho geral) permitindo uma comunicação homem-máquina; e Modo 3 - Possibilitar o controle da via principal com base na utilização de sensores de presença nas vias de mão dupla.

Ao término do projeto, os tempos vigentes da interseção foram identificados em displays de 7 segmentos, dois para cada semáforo, possibilitando a verificação decrescendo do tempo, além da identificação visual com Led's dos sinais verde, amarelo e vermelho (Figuras 8 e 9).

Além disso, e considerando que qualquer recurso didático é valido para melhorar a explicação de determinado assunto em sala de aula, foi proposto que o Curso de Arquitetura e Urbanismo colaborasse com a execução de uma maquete da área analisada bem como a simulação da situação semafórica existente e da situação ideal, facilitando a compreensão da aplicação do estudo e materializando as conclusões do mesmo, conforme mostra a Figura 8.

Figura 8 - Imagem da maquete construída, incorporando os trabalhos das disciplinas de Engenharia de Tráfego II, Análise e Projeto de Sistemas Lógicos Programáveis e Modelagem.

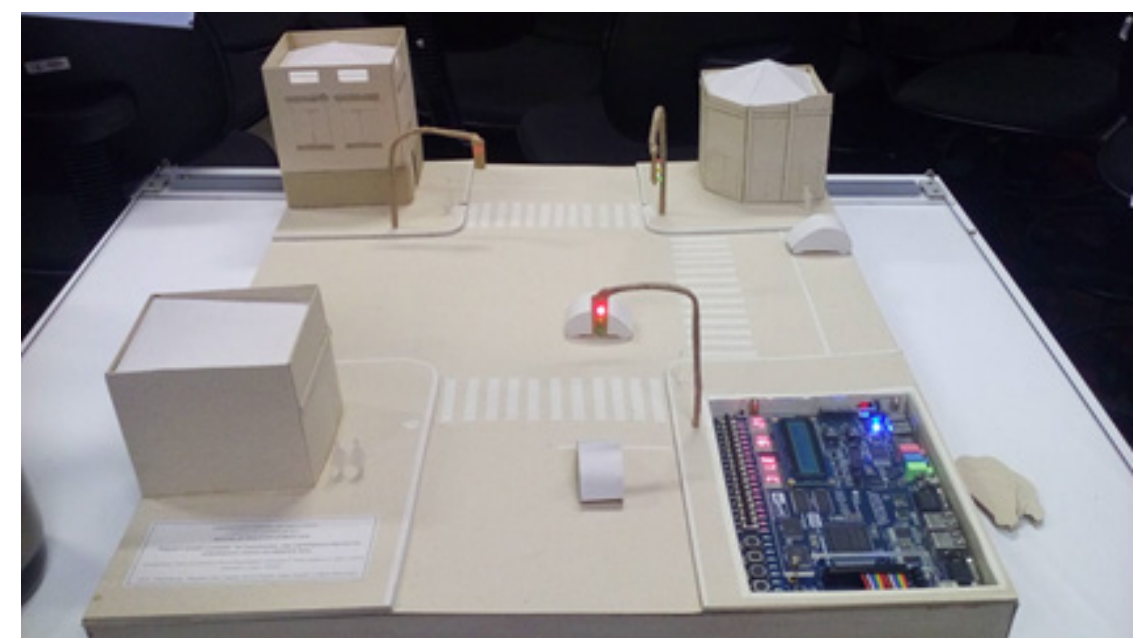


Figura 9 - Registro da Placa de comando dos semáforos com as conexões que foram colocadas abaixo da base da maquete.

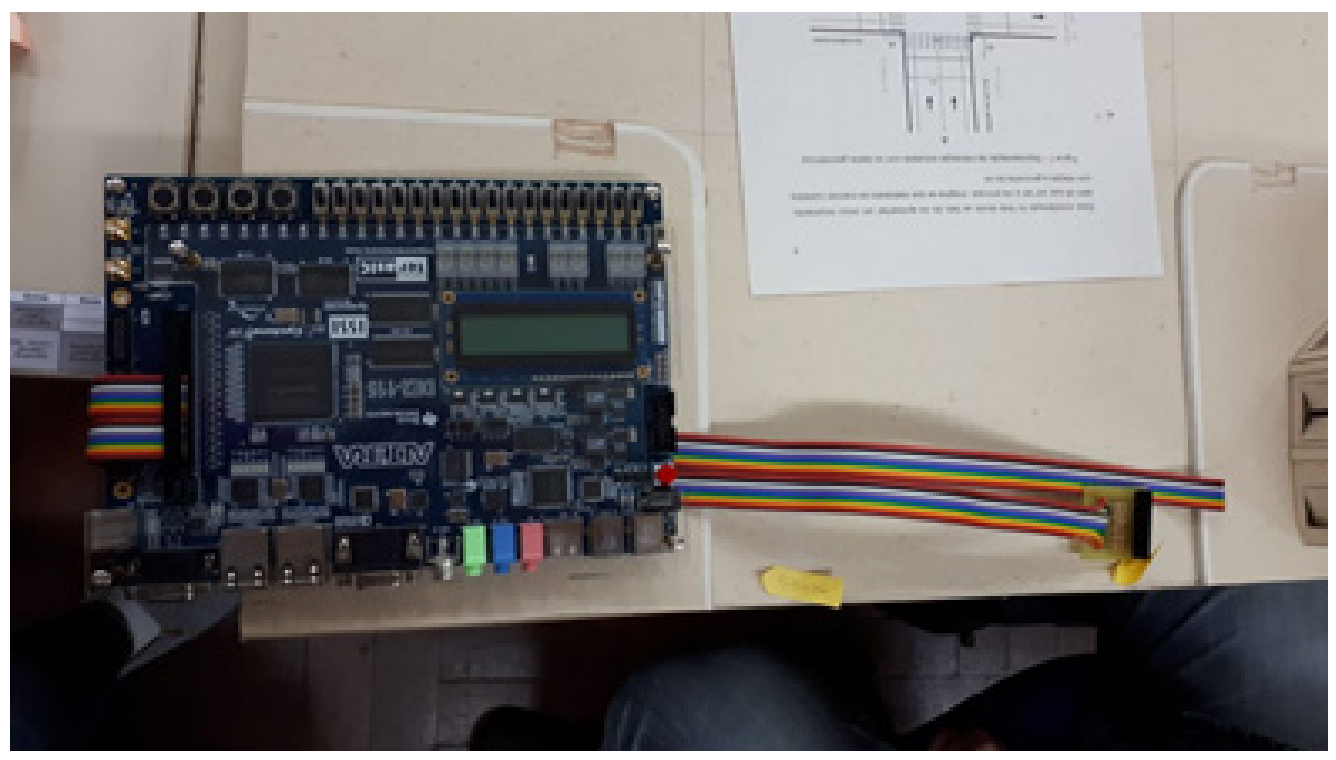

Enfim, os trabalhos concluíram que a programação semafórica vigente na interseção continha tempos inadequados e sugeriu modificações que, caso implantadas, contribuiriam para a otimização do fluxo de veículos na interseção bem como o aumento da segurança no local. Além disso, a interdisciplinaridade só enriqueceu os resultados e principalmente os meios de apresentação deles, deixando mais lúdico e real e assim possibilitando a aproximação da temática do trabalho, até por quem não é da área das ciências tecnológicas. Também a troca de ideias e conexões entre as diversas áreas foi um campo de experimentação não apenas para os alunos mas para os docentes, que coordenavam suas frentes de trabalho e frequentemente se dedicavam a entender o que a outra disciplina precisava e como seria os ajustes entre elas.

\section{Considerações finais}

A aplicação de metodologias de ensino relacionadas ao Project-Based Learning proporcionou aos alunos diversas experiências práticas, onde foi possível desenvolver e aplicar teorias vistas em sala de aula a casos reais, tornando a aprendizagem mais ampla, completa e dinâmica. As experiências desenvolvidas em disciplinas profissionalizantes dos cursos de graduação da Universidade Federal de Santa Maria - Campus Cachoeira do Sul permitiram que os alunos pudessem comprovar como o profissional de engenharia aplica os conceitos estudados, vivenciando os processos de forma realista.

Por um lado, o realismo do trabalho proposto aplicado na disciplina de Projeto Geométrico de Rodovias ajudou na compreensão e fixação do conteúdo. Além disso, a apresentação dos trabalhos em audiência pública com o envolvimento de corpo técnico especializado nas áreas atuantes da disciplina estimulou o desenvolvimento responsável do projeto por parte dos alunos. Igualmente, a apresentação de indicadores de desempenho do projeto realizado na disciplina para a competição com os alunos da UFRGS permitiu a integração entre as universidades, dando a oportunidade de troca de experiências.

Já o caso aplicado do trabalho desenvolvido nas disciplinas de Engenharia de Tráfego II e Sistemas Lógicos Programáveis possibilitou a integração entre duas áreas da engenharia, o que exemplifica casos da vida profissional, em que para o desenvolvimento de algumas atividades deverá haver uma comunicação entre diversas áreas. Além de que a atividade foi aplicada ao caso de uma análise semafórica de uma interseção real possibilitando a integração da universidade com a sociedade, podendo ainda esses resultados contribuírem para a realização de melhorias no locais em estudo.

A aplicação dessa metodologia nas disciplinas dos cursos de engenharia reportadas neste artigo foi satisfatória, visto que os alunos tiveram diversas oportunidades de aprendizado que não seriam tangíveis seguindo as metodologias tradicionais de aprendizado. Dentre as experiências proporcionadas com essa metodologia, fica evidente que os alunos desenvolveram habilidades de comunicação, trabalho em equipe, tomada de decisão e autoaprendizagem. Desta forma, acredita-se que com o estímulo ao desenvolvimento de tarefas como essas reportadas neste artigo, os alunos de engenharia desenvolvem experiências práticas que irão auxiliá-los na sua formação profissional, preparando-os alunos para as exigências do atual mercado de trabalho competitivo na engenharia, que exige habilidades em cenários dinâmicos e contingentes. 


\section{Agradecimentos}

Os autores agradecem a colaboração do Prof. Dr. Daniel Sergio Presta Garcia, responsável da disciplina de Rodovias do Curso de Engenharia Civil da UFRGS, assim como a todos os acadêmicos dos cursos de graduação da UFSM-CS que participaram das experiências nas disciplinas envolvidas.

\section{Referências}

BARROWS H S. A specific, problem-based, self-directed learning method designed to teach medical problem-solving skills, self-learning skills and enhance knowledge retention and recall. In H. G. Schmidt, \& M. L. de Volder (Eds.), Tutorials in problem-based learning. A new direction in teaching the health profession. Assen: Van Gorcum, 1984.

CARDOSO J P P C, MORAIS L C, RODRIGUES C A, BITTENCOURT, R A. Introduzindo a programação de computadores e PBL com python e app inventor. COBENGE. XLIII Congresso Brasileiro de Educação em Engenharia. São Paulo. 20CHANG C-H, CHEN Y-Y, WANG J-C, WANG S-C, WU C. The case study of team-based learning methodology with teachers of four domains in the senior high school. Procedia - Social and Behavioral Sciences n. 176, 804-810, 2015.

CONFEDERAÇÃO NACIONAL DA INDÚSTRIA- CNI. Fortalecimento das engenharias. Mobilização Empresarial pela Inovação. Brasília: Confederação Nacional da Indústria, 2015.

DALE E. Audio-visual methods in teaching, New York: The Dryden Press, 1946.

DEMORE C P, LANES T K, GARCÍA D S P, NODARI C T, ALBANO J F, WANDSCHEER M A, DOS SANTOS F F F, ANDRIOLA C L. Projeto ponto de partida: o ensino de projetos de rodovias através de uma abordagem lúdicoreal-didática. Transportes, v. 25, n. 3, 153-165, 2017.

INEP. Censo da Educação Superior 2015. Ministério da Educação. Brasília: Instituto Nacional de Estudos e Pesquisas Educacionais Anísio Teixeira, 2015.

MICHAELSEN L K, KNIGHT A B, FINK L D. Team-Based Learning: A transformation of Small Groups in College Teaching. Sterling, VA: Stylus Publishing, LLC, 2004.

MILLS J E, TREAGUST D. Engineering Education, Is Problem-Based or Project-Besed Learning the Answer? Australasian Journal of Engineering Education, 2003. Disponível em: http://www.aaee.com.au/journal/2003/ mills treagust03.pdf. Acesso em: 17/08/2018.

NGUYEN, D. Q. The Essential Skills and Attributes of an Engineer: A Comparative Study of Academics, Industry Personnel and Engineering Students. Global Journal of Engineering Education: Melbourne, v. 2, n. 1, p. 65-76, 1998.

PASSOS F L, HERDY F H, PASSOS F V. Aprendizado baseado em problema: O PBL nos cursos de engenharia e arquitetura no Brasil. Congresso Brasileiro de Produção em Engenharia, 38, Fortaleza, 2010.

RIBEIRO, L R C. A aprendizagem baseada em problemas (PBL): Uma implementação na educação em engenharia na voz dos atores. Tese (Doutorado) - Universidade Federal de São Carlos. São Carlos: UFSCar, 209 p., 2005.

SILVA T T. Teorias do currículo: uma introdução crítica. Porto: Porto Editora, 2000.

THOMAS J W. A review of research on project-based learning. The autodesk Foundation. California: San Rafael, 46 p., 2000.

TRASOBARES A H, GILABERTE R L. Aplicación del aprendizaje basado en problemas (PBL) bajo un enfoque multidisciplinar: una experiencia práctica. Conocimiento, innovación y emprendedores: Camino al futuro/ coord. por Juan Carlos Ayala Calvo. Universidad de Zagaroza. p. 30- 43, 2007.

YIN R K. Estudo de caso: planejamento e métodos. 2 Ed. Porto Alegre: Bookman, 2001. 